\title{
Measuring $\beta$-diversity by remote sensing: A challenge for biodiversity monitoring
}

\author{
Duccio Rocchini $^{1,2,3}$ (D) | Sandra Luque ${ }^{4}$ (i) | Nathalie Pettorelli ${ }^{5}$ (D) | Lucy Bastin ${ }^{6}$ (D) | \\ Daniel Doktor $^{7}$ | Nicolò Faedi ${ }^{3,8}$ | Hannes Feilhauer9 (D) | Jean-Baptiste Féret ${ }^{4}$ (D) | \\ Giles M. Foody ${ }^{10}$ (D) | Yoni Gavish ${ }^{11}$ (D) | Sergio Godinho ${ }^{12}$ | William E. Kunin ${ }^{13}$ (D) | \\ Angela Lausch $^{7}$ (D) | Pedro J. Leitão ${ }^{14,15}$ (D) | Matteo Marcantonio ${ }^{16}$ | Markus Neteler ${ }^{17}$ (D) | \\ Carlo Ricotta $^{18}$ (ID) | Sebastian Schmidtlein ${ }^{19}$ | Petteri Vihervaara ${ }^{20}$ | \\ Martin Wegmann ${ }^{21}$ (D) | Harini Nagendra ${ }^{22}$ (i)
}

${ }^{1}$ Center Agriculture Food Environment, University of Trento, S. Michele all'Adige (TN), Italy; ${ }^{2}$ Centre for Integrative Biology, University of Trento, Povo (TN), Italy; ${ }^{3}$ Department of Biodiversity and Molecular Ecology, Fondazione Edmund Mach, Research and Innovation Centre, S. Michele all'Adige (TN), Italy; ${ }^{4} U M R-$ TETIS, IRSTEA Montpellier, Maison de la Télédétection, Montpellier Cedex 5, France; ${ }^{5}$ Institute of Zoology, The Zoological Society of London, London, UK; ${ }^{6}$ School of Computer Science, Aston University, Birmingham, UK; ${ }^{7}$ Department Computational Landscape Ecology, Helmholtz Centre for Environmental Research - UFZ, Leipzig, Germany; ${ }^{8}$ Department of Computer Science and Engineering, University of Bologna, Bologna, Italy; ${ }^{9}$ Institut für Geographie FriedrichAlexander, Universität Erlangen-Nürnberg, Erlangen, Germany; ${ }^{10}$ School of Geography, University of Nottingham, Nottingham, UK; ${ }^{11}$ School of Biology, Faculty of biological Science, University of Leeds, Leeds, UK; ${ }^{12}$ Institute of Mediterranean Agricultural and Environmental Sciences (ICAAM), Universidade de Evora, Evora, Portugal; ${ }^{13}$ School of Biology, University of Leeds, Leeds, UK; ${ }^{14}$ Department Landscape Ecology and Environmental System Analysis, Technische Universität Braunschweig, Braunschweig, Germany; ${ }^{15}$ Geography Department, Humboldt-Universität zu Berlin, Berlin, Germany; ${ }^{16}$ Department of Pathology, Microbiology, and Immunology, School of Veterinary Medicine, University of California, Davis, CA, USA; ${ }^{17}$ Mundialis GmbH \& Co. KG, Bonn, Germany; ${ }^{18}$ Department of Environmental Biology, University of Rome "La Sapienza", Rome, Italy; ${ }^{19}$ Karlsruher Institut für Technologie (KIT), Institut für Geographie und Geoökologie, Karlsruhe, Germany; ${ }^{20}$ Natural Environment Centre, Finnish Environment Institute (SYKE), Helsinki, Finland; ${ }^{21}$ Department of Remote Sensing, Remote Sensing and Biodiversity Research Group, University of Wuerzburg, Wuerzburg, Germany and ${ }^{22}$ Azim Premji University, Bangalore, India

Correspondence

Duccio Rocchini

Emails: ducciorocchini@gmail.com;

duccio.rocchini@fmach.it

Present address

Lucy Bastin, Knowledge Management

Unit, Joint Research Centre of the European

Commission, Ispra, Italy

Handling Editor: Francesca Parrin

\section{Abstract}

1. Biodiversity includes multiscalar and multitemporal structures and processes, with different levels of functional organization, from genetic to ecosystemic levels. One of the mostly used methods to infer biodiversity is based on taxonomic approaches and community ecology theories. However, gathering extensive data in the field is difficult due to logistic problems, especially when aiming at modelling biodiversity changes in space and time, which assumes statistically sound sampling schemes. In this context, airborne or satellite remote sensing allows information to be gathered over wide areas in a reasonable time.

2. Most of the biodiversity maps obtained from remote sensing have been based on the inference of species richness by regression analysis. On the contrary, estimating compositional turnover ( $\beta$-diversity) might add crucial information related to relative abundance of different species instead of just richness. Presently, few studies have addressed the measurement of species compositional turnover from space.

3. Extending on previous work, in this manuscript, we propose novel techniques to measure $\beta$-diversity from airborne or satellite remote sensing, mainly based on: (1) multivariate statistical analysis, (2) the spectral species concept, (3) self-organizing 
feature maps, (4) multidimensional distance matrices, and the (5) Rao's Q diversity. Each of these measures addresses one or several issues related to turnover measurement. This manuscript is the first methodological example encompassing (and enhancing) most of the available methods for estimating $\beta$-diversity from remotely sensed imagery and potentially relating them to species diversity in the field.

\section{KEYWORDS}

$\beta$-diversity, Kohonen self-organizing feature maps, Rao's Q diversity index, remote sensing, satellite imagery, sparse generalized dissimilarity model, spectral species concept

\section{1 | INTRODUCTION}

Biodiversity cannot be fully investigated without considering the spatial component of its variation. In fact, it is known that the dispersal of species over wide areas is driven by spatial constraints directly related to the distance among sites. A negative exponential dispersal kernel is usually adopted to mathematically describe the occupancy of new sites by species, as follows:

$$
F=\sum_{K=1}^{N} e^{\frac{-d_{i k}}{a}}
$$

where $d_{i k}=$ distance between two locations $i$ and $k$ and $a$ is a parameter regulating the dispersal from localized areas (low values of $a$ ) to widespread ones (high values of $a$; Meentemeyer, Anacker, Mark, \& Rizzo, 2008).

In this sense, distance acquires a significant role in ecology to estimate biodiversity change. Hence, spatially explicit methods have been acknowledged in ecology for providing robust estimates of diversity at different hierarchical levels: from individuals (Tyre, Possingham, \& Lindenmayer, 2001), to populations (Vernesi et al., 2012), to communities (Rocchini, Andreini Butini, \& Chiarucci, 2005).

When dealing with spatial explicit methods, remote sensing images represent a powerful tool (Rocchini et al., 2017), particularly when coupling information on compositional properties of the landscape with its structure (Figure 1). Remote sensing has widely been used for conservation practices including very different types of data such as night lights data (Mazor et al., 2013), Land Surface Temperature estimated from MODIS data (Metz, Rocchini, \& Neteler, 2014), spectral indices (Gillespie, 2005).

Most of the remote sensing applications for biodiversity estimation have relied on the estimate of local diversity hotspots, considering land use diversity (Wegmann et al., 2017) or continuous spatial variability of the spectral signal (Rocchini et al., 2010). This is mainly grounded in the assumption that a higher landscape heterogeneity is strictly related to a higher amount of species occupying different niches (Scmheller et al., in press). However, given two sites $s_{1}$ and $s_{2}$, the final diversity is not only related to the species/spectral richness of $s_{1}$ and $s_{2}$, but overall to the amount of shared species/ spectral values. In other words, the lower the their intersection $s_{1} \cap s_{2}$ the higher will be the total diversity, while the lowest total diversity will be reached when $s_{1} \cap s_{2}=s_{1} \cup s_{2}$. Such intersection has been widely studied in ecology, after the development of $\beta$-diversity theory (Whittaker, 1960).

Tuomisto et al. (2003) demonstrated the power of substituting distance in Equation 1 by spectral distance to directly account for the distance between sites in an environmental space, instead of a merely spatial one. However, while spectral distance examples exist when measuring the $\beta$-diversity among pairs of sites (e.g., Rocchini, Hernández Stefanoni, \& He, 2015), few studies have tested the possibility of measuring $\beta$-diversity over wide areas considering several sites at the same time (however see Alahuhta et al., 2017; Harris, Charnock, \& Lucas, 2015). This is especially true when considering the development of remote sensing tools (Rocchini \& Neteler, 2012) for diversity estimate in which the concept of $\beta$-diversity is still pioneering.

The aim of this paper is to present the most novel methods to measure $\beta$-diversity from remotely sensed imagery based on the most recently published ecological models. In particular, we will deal with: (1) multivariate statistical techniques, (2) the applicability of the spectral species concept, (3) multidimensional distance matrices, (4) metrics coupling abundance and distance-based measures.

This manuscript is the first methodological example encompassing (and enhancing) most of the available methods for estimating $\beta$-diversity from remotely sensed imagery and potentially relate them to species diversity in the field.

\section{2 | MULTIVARIATE STATISTICAL ANALYSIS FOR SPECIES DIVERSITY ESTIMATE FROM REMOTE SENSING}

Univariate statistics have been used to directly find relations between spectral and species diversity. However, the amount of variability explained by single bands/vegetation indices versus species diversity is generally relatively low, due to the fact that different aspects related to the complexity of habitats might act in shaping diversity, from disturbance and land use at local scales to climate and element fluxes at global scales.

Ordination techniques are designed to quantitatively describe multivariate gradual transitions in the species composition of sampled sites. Measuring the distance between two sampling sites in the multidimensional ordination space is a good proxy of the change in species composition. When this measure is related to the geographical distance 


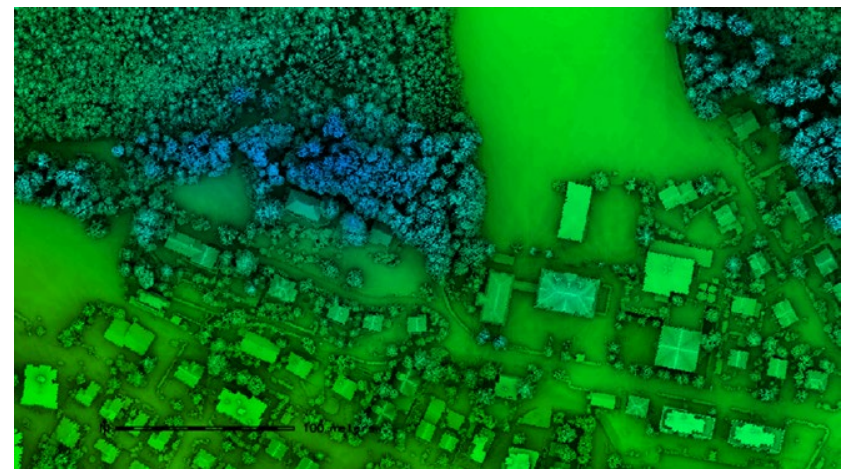

FIGURE 1 An example of how to couple information on compositional properties of the landscape by optical data together with structural (3D) properties by laser scanning LiDAR data

between the considered sites, the beta diversity at this particular scale can be assessed.

Of the various available ordination techniques, detrended correspondence analysis (DCA; Hill \& Gauch, 1980) is particularly suitable for such analyses. The axes (i.e., gradients) of the DCA ordination space are scaled in SD units, where a distance of $4 S D$ is related to a full species turnover. This enables a versatile analysis that easily reveals whether two sampled sites still have species in common.

Several studies have mapped the ordination space using remote sensing data (e.g., Feilhauer \& Schmidtlein, 2009; Feilhauer, Faude, \& Schmidtlein, 2011; Feilhauer et al., 2014; Gu, Singh, \& Townsend, 2015; Harris et al., 2015; Leitão et al., 2015; Neumann et al., 2015; Schmidtlein \& Sassin, 2004; Schmidtlein, Zimmermann, Schüpferling, $\&$ Weiss, 2007). For this purpose, the axes scores of the sampled sites are regressed against the corresponding canopy reflectance values extracted from air- or spaceborne image data. The resulting multivariate regression models, one per ordination axis and most often generated with machine learning regression techniques, are subsequently applied on the image data for a spatial prediction of ordination scores. Each pixel of the image data is assigned to a specific position in the ordination space that indicates its species composition. The resulting gradient maps are a powerful tool for analyses of beta diversity across different spatial scales (Feilhauer \& Schmidtlein, 2009; HernandezStefanoni et al., 2012).

A simple analysis of the variability of the DCA scores in a defined pixel neighbourhood (i.e., a moving window) results in a efficient beta diversity assessment. The spatial scale of this assessment can be varied either by resampling the gradient map to a coarser spatial resolution (i.e., pixel size) or by changing the kernel size of the considered pixel neighbourhood. Such techniques have been further developed e.g. for spatial conservation prioritization programmes such as Zonation (Moilanen et al., 2005; Moilanen, Kujala, \& Leathwick, 2009).

Figure 2 shows an example of a DCA-based assessment of beta diversity on a very local scale $(10 \mathrm{~m})$ following the approach described in Feilhauer and Schmidtlein (2009). The analysed landscape is a mosaic of raised bogs, fens, transition mires and Molinia meadows. For a detailed description of the data and site please refer to Feilhauer et al. (2014) and Feilhauer, Doktor, Schmidtlein, and Skidmore (2016).

Analyses like this require two different datasets: (1) a sample of field data that is representative for the vegetation in the studied area and is used to generate the ordination space; (2) image data with a sufficient spectral resolution to discriminate the vegetation types within the ordination space and with a spatial resolution that is in line with the sampling design of the field data (Feilhauer et al., 2013).

\section{(a) DCA ordination space}

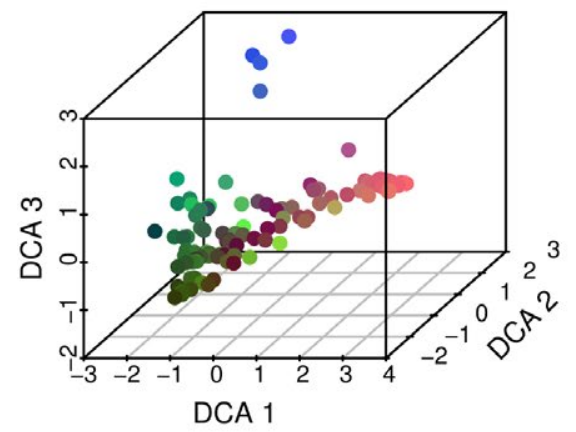

(b) Gradient map

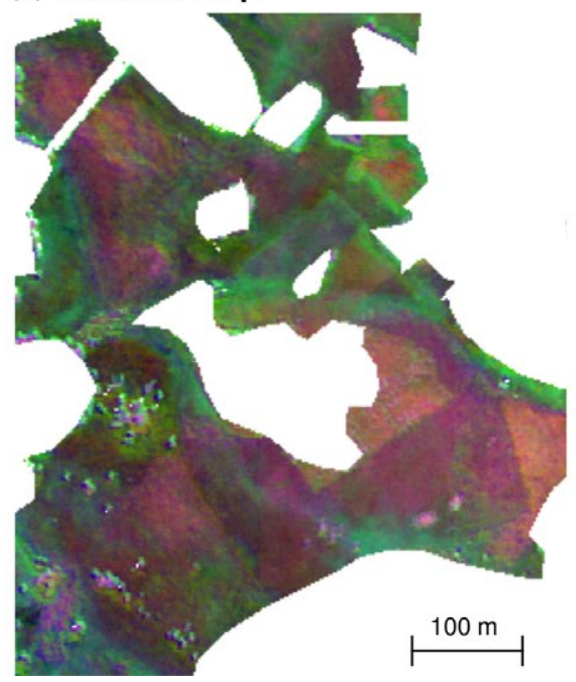

(c) Beta diversity $/ 10 \mathrm{~m}$

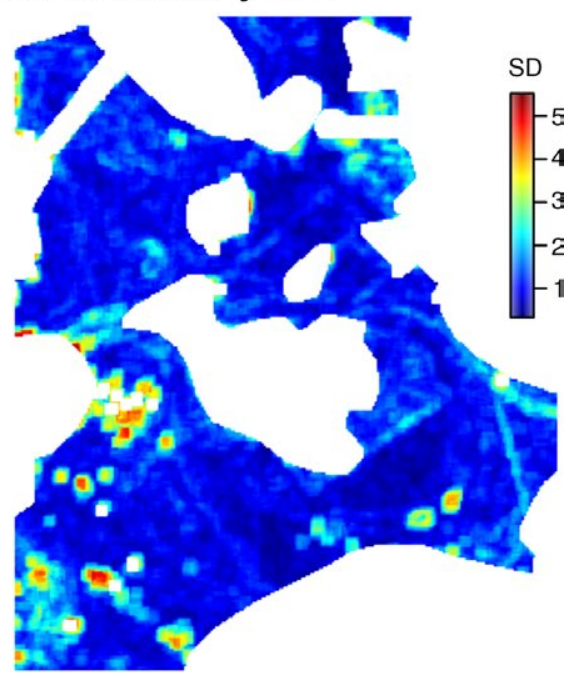

FIGURE $2 \beta$-diversity assessment with a combination of ordination techniques and remote sensing. (a) Three-dimensional detrended correspondence analysis (DCA) ordination space of $n=100$ vegetation plots sampled in raised bogs, fens, transition mires and Molinia meadows in the alpine foothills of Southern Germany. An inter-plot distance of 4 SD corresponds to a full species turnover. (b) Maps of the ordination axes resulting from a spatial prediction based on canopy reflectance. Each pixel has a predicted position in the ordination space that is indicated by its colour. The colour scheme corresponds to (a). The map has a spatial resolution of $2 \times 2 \mathrm{~m}^{2}$, which is in line with the sampled plot size.

(c) Cumulative change rates along the three DCA axes in a $5 \times 5$ pixel neighbourhood. A high change rate indicates a high beta diversity 
Using these data, the continuous spatial variability of the spectral signal in the image pixels is translated into a spatially continuous measure of species composition. The advantages of this approach are obvious: since the diversity analyses are conducted in the floristic gradient space, the resulting measures resemble field studies and are thus easier to interpret than spectral proxies and closer to the point of view of many end-users. Furthermore, the analysis of ordination scores in defined pixel neighbourhoods is not restricted to a single spatial scale but offers the opportunity to implement assessments of beta diversity on multiple scales.

\section{3 | THE SPECTRAL SPECIES CONCEPT}

The spectral species concept has been proposed by Féret and Asner (2014a) to map both $\alpha$ and $\beta$ component of the biodiversity using a unique framework. It is rooted in the convergence between two other concepts, the spectral variation hypothesis (SVH) proposed by Palmer, Earls, Hoagland, White, and Wohlgemuth (2002), and the plant optical types proposed by Ustin and Gamon (2010), sustained by the technological advances in the domain of high spatial resolution imaging spectroscopy. The SVH states that the spatial variability in the remotely sensed signal, that is the spectral heterogeneity, is related to environmental heterogeneity and could therefore be used as a powerful proxy of species diversity. SVH has been tested in different situations (Rocchini et al., 2010) and conclusions show that the performance of this approach is very dependent on several factors, including the instrument characteristics (spectral, spatial and temporal resolution), the type of vegetation investigated, and the metrics derived from remotely sensed information to estimate spectral heterogeneity. Plant optical types refer to the capacity of sensors to measure signals that aggregate information about vegetation structure, phenology, biochemistry and physiology. Therefore, this concept is also tightly linked to the performances of the sensor and finds particular echo with the increasing use of high spatial resolution imaging spectroscopy for the estimation and identification of multiple vegetation properties.

The details provided by high spatial resolution imaging spectroscopy are sufficient to perform analyses of plant optical traits at the individual tree scale in order to differentiate tree species, obtain information about leaf chemical traits and estimate the $\alpha$ component of biodiversity (Asner \& Martin, 2008; Asner, Martin, Anderson, \& Knapp, 2015; Chadwick \& Asner, 2016; Clark \& Roberts, 2012; Clark, Roberts, \& Clark, 2005; Féret \& Asner, 2013; Vaglio Laurin et al., 2014). These results illustrate that spectral information can be related to taxonomic or functional information of the vegetation, which supports the SVH under the hypothesis that the metrics used to compute spectral heterogeneity and a given component of vegetation diversity are properly defined. However these applications are currently limited by the important amount of field data required to train regression or classification models, which is also directly linked to their low generalization ability in time and space. Unsupervised approaches then appear as valuable alternatives for the analysis of ecosystem heterogeneity
(Baldeck \& Asner, 2013; Baldeck et al., 2014; Feilhauer, Faude, \& Schmidtlein, 2011; Féret \& Asner, 2014b), as ecological indicators of $\alpha$ and $\beta$ diversity at landscape scale usually require one or several levels of abstraction beyond the correct taxonomic identification (Tuomisto \& Ruokolainen, 2006).

Clustering (properly pre-processed) spectral information should result in pixels from the same species naturally grouping together rather than distributing randomly among clusters, Féret and Asner (2014a) proposed a grouping method aiming at assigning labels to pixels based on multiple clustering of spectroscopic data acquired at landscape scale. These pixels, labelled with a set of the so-called spectral species, can then be used straightforwardly in order to compute various diversity metrics such as Shannon index for $\alpha$ diversity, and Bray-Curtis dissimilarity for $\beta$ diversity. The pre-processing stage is divided into several stages. After masking all non-vegetated pixels, a normalization based on continuous removal is applied to each pixel and over the full spectral domain, then a principal component analysis is performed on the continuously removed spectral data. The normalization reduces effects due to changes in illumination, canopy geometry and other factors unrelated to vegetation, while enhancing the signal corresponding to vegetation. The components including individual-specific information are the components of interest. They can be identified after visual inspection or automated routines, if initial data show sufficient signal to noise ratio. Once a limited number of components have been selected, $k$-means clustering is then applied to a certain number of subsets, and for each of these subsets, centroids are computed and each pixel in the image is labelled based on the closest centroid. The repetition of clustering based on various subsets of the image tends to minimize the risk of assigning centroids to irrelevant groups of pixels. Experimental results showed that the averaging of diversity indices computed from multiple centroid maps can be seen as an analogous to signal averaging, which consists in increasing signal to noise ratio by replicating measurements. For each repetition, the closest centroid corresponds to the spectral species, and for each spatial unit of a given size, the spectral species distribution is derived in order to compute any diversity metric requiring either information at the local scale, or comparison of information across spatially distant plots.

The concepts of spectral species and spectral species distribution have been tested successfully on a limited number of situations and types of ecosystems (see Rocchini et al., 2016 for a review, and Lausch et al., 2016 for an application to similar concepts). As an example, Féret and Asner (2014a) showed ability to properly estimate landscape heterogeneity at moderate spatial scale, up to few dozen square kilometers over tropical forests, based on high spatial resolution imaging spectroscopy (Figure 3). A generic parameterization of the method showed robust performances for $\alpha$ diversity mapping across space and time, but mapping $\beta$ diversity across large spatial scales using images acquired during different airborne campaign remains challenging, which leads to an unsolved problem when considering operational regional mapping. In the perspective of global monitoring of biodiversity, and given the unprecedented remote sensing capacity allowed by the Copernicus program, including the Sentinel-2 multispectral satellites, several other challenges are foreseen and currently investigated. The 


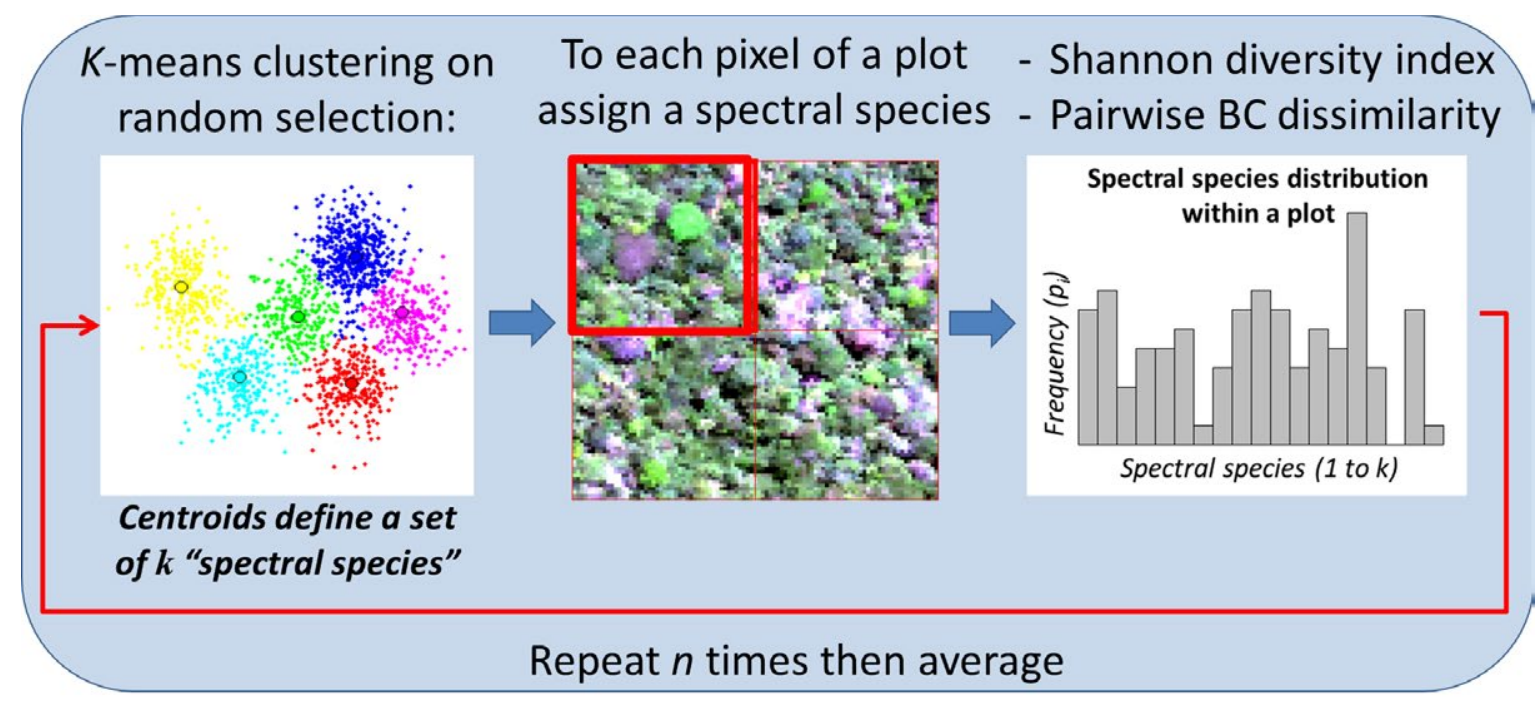

\section{RGB}

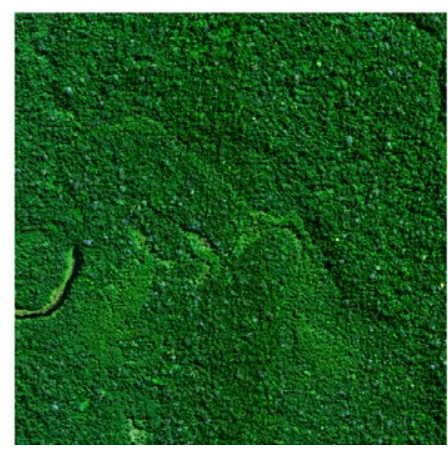

$\alpha$-diversity

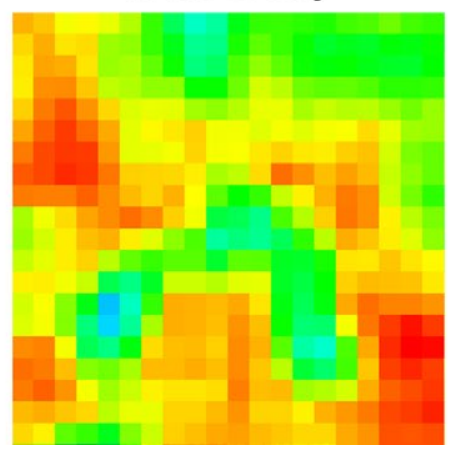

$\beta$-diversity

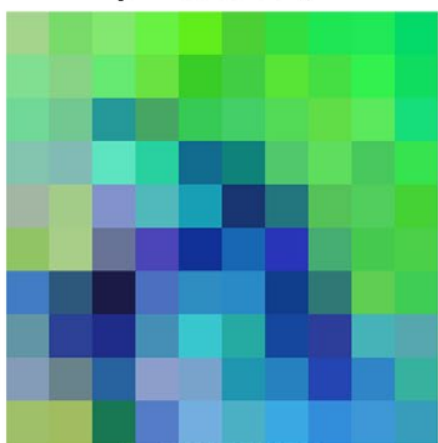

FIGURE 3 Spectral species can be identified in a hyper- or multispectral image by spatial clustering method and their distribution can be mapped. Such maps can further be used to apply local-based heterogeneity measurements ( $\alpha$-diversity) as well as iterative distance-based methods to build $\beta$-diversity maps. Reproduced from Féret and Asner (2014a)

influence of decreased spatial and spectral resolution on the ability to properly differentiate ecologically meaningful spectral species across landscapes and over regions will need to be investigated. The application of this concept beyond tropical forests and savanna ecosystems should also be investigated, as it may not hold when applied on moderately diverse ecosystems or systems with individuals whose individuals have dimensions well below the resolving power of the instrument.

\section{SELF-ORGANIZING FEATURE MAPS}

The Kohonen self-organizing feature map (SOFM; Kohonen, 1982) is a neural network that may be used to undertake unsupervised clustering of data. Critically, the input to a SOFM can be a large multi-variate dataset such as may be acquired on species from quadrat-based field surveys. The SOFM summarizes the data in a low, typically two, dimensional output (Figure 4). In this output space, the data for individual quadrats are topologically ordered-with sites that are similar close together while those of highly different species composition are more distant. Because the data sites in the output space are arranged by

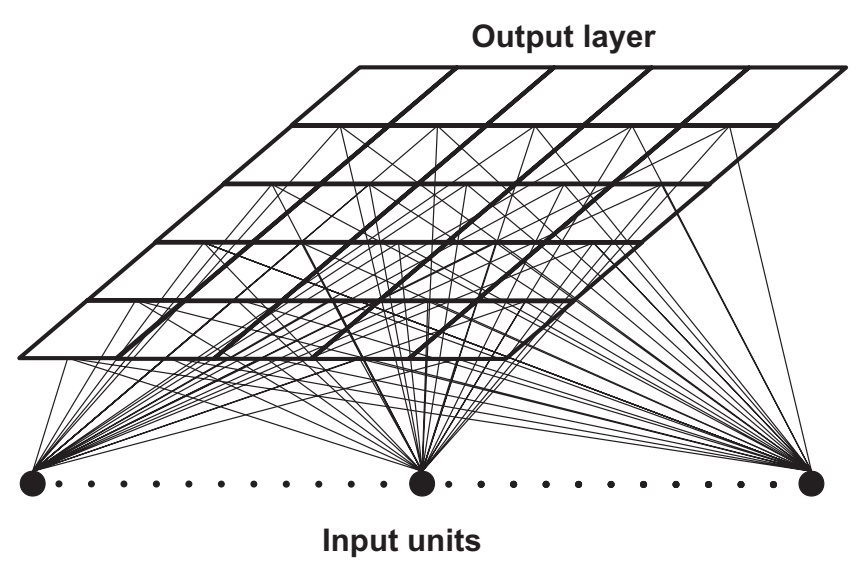

FIGURE 4 A self-organizing feature map can be built starting from an input layer, e.g. the presence or absence of a tree species or of a peculiar spectral value) which is connected to every unit in the output layer by a weighted connection. The self-organizing feature map uses unsupervised learning to map the location of field sites within the output space on the basis of their relative similarity in species or spectral composition. Redrawn from Foody and Cutler (2003) 
relative similarity the output space may also be used to aggregate or classify a dataset. As such the SOFM is attractive as a non-parametric clustering analysis and as a means to undertake an ordination (Chon, Park, Moon, \& Cha, 1996).

A SOFM is, unlike some of the approaches used commonly in community ecology, not constrained by assumptions relating the statistical distribution of the data used. The SOFM uses unsupervised learning to produce a topologically ordered output space in which the samples are arranged spatially in relation to their relative similarity in species composition. The SOFM thus performs a non-parametric ordination analysis (Foody, 1999). The production of a classification by a SOFM comprises two main stages (Giraudel \& Lek, 2001). An iterative analysis, in which time-decaying parameters that control network learning and the size of local neighbourhoods located around output units, is used. For this, the user must specify a number of key parameters such as the size and shape of the network, number of iterations of the algorithm, the learning rate and its rate of decline and a neighbourhood parameter. The need for such parameters can add some uncertainty to the analysis. While there are no formal rules to follow in the design of a SOFM there are recommendations for the determination of SOFM parameter settings (Giraudel \& Lek, 2001). A further concern is that as an unsupervised classifier, the classes defined may not always be the most useful for an investigation. In addition, the nature of the analysis means the direction of the gradients cannot be controlled (Fritzke, 1995) but the analysis performs well in comparison to popular ordination techniques such as PCA and DCA (Foody \& Cutler, 2003). The SOFM may also use a variety of different data types such as presence/absence, abundance or importance values and can solve complex nonlinear problems (Giraudel \& Lek, 2001).

\section{5 | MULTIDIMENSIONAL DISTANCE MATRICES: GDMS AND SGDMS}

One of the most widespread methods for assessing diversity is using distance matrices (Legendre, Borcard, \& Peres-Neto, 2005). Indeed, early work by Whittaker (1960) suggested that $\beta$-diversity could be quantified by dissimilarity matrices among (pairs of) sites. Furthermore, the Mantel test (Mantel \& Valand, 1970), designed to estimate the association between two independent dissimilarity matrices, has been widely used to correlate a community composition dissimilarity matrix with an environment dissimilarity one, thus providing useful insights into community composition and turnover (Legendre et al., 2005; Tahvanainen, 2011).

Generalized dissimilarity modelling (GDM; Ferrier, Manion, Elith, \& Richardson, 2007) can be considered as an extension of the Mantel test, which is able to accommodate multidimensional environmental data, to be compared with the compositional data. GDMs also allow for the prediction of compositional turnover as well as for, e.g. environmental classification constrained to the compositional dissimilarity (Ferrier et al., 2007; Leathwick et al., 2011). In GDM, the compositional dissimilarities between all pairs of samples are modelled as a function of their respective environmental distances. This is done through a linear combination of monotonic I-spline basis functions, under the assumption that increasing environmental dissimilarity (e.g., along a gradient) can only result in increasing compositional dissimilarity. This method is thus well suited for measuring and mapping $\beta$-diversity, and is thus becoming widely used in conservation science and macroecology, and recently been subject to several developments as we describe below.

One such development is the phylogenetic GDM (phylo-GDM; Rosauer et al., 2014), which incorporates phylogenetic dissimilarities into GDM and allows for analysing and predicting phylogenetic $\beta$-diversity, thus linking ecological and evolutionary processes. This method can provide novel insights into the mechanisms underlying current patterns of biological diversity (Graham \& Fine, 2008). Another recent development of GDM is the multi-site GDM (MS-GDM; Latombe, Hui, \& McGeoch, 2017), which extends GDMs from pairwise to multi-site dissimilarity modelling. In such a paper, the authors tested MS-GDM by means of both constrained (monotonical) additive models and I-splines, although with no conclusive results relating to the best method overall. They concluded, however, that when applying MS-GDM to a high number of samples, they could better explain the drivers of species turnover. Also, an important development of GDM is the Bayesian bootstrap GDM (BBGDM; Woolley, Foster, O'Hara, Wintle, \& Dunstan, 2017) designed to characterize uncertainty in generalized dissimilarity models. This approach allows better representing the underlying uncertainty in the data, by estimating the variance in parameters based on the available data.

Finally, an implementation of GDM, which was created particularly for dealing with high-dimensional (and potentially high-collinear) remote sensing data as input in GDM is the sparse generalized dissimilarity model (SGDM; Figure 5; Leitão et al., 2015). This method is a two-stage approach that consists of initially reducing the environmental space (e.g., reflectance data) by means of a sparse canonical correlation analysis (SCCA; Figure 5; Witten, Tibshirani, Gross, \& Narasimhan, 2013), and then fitting the resulting components with a GDM model. The SCCA is a form of penalized canonical correlation analysis based on the L1 (lasso) penalty function, and is thus designed to deal with high-dimensional data. The two algorithms are coupled in a way that the SCCA penalization is selected through a heuristic grid search manner, in order to minimize the cross-validate root mean square error in the dissimilarities predicted by the GDM. In this procedure, the high-dimensional environmental data (such as coming from time series of multispectral or hyperspectral data) are subject to a supervised ordination approach that reduces their dimension while capturing the axes of variation that most correlate to those of the community compositional matrix. SGDM has been successfully used for modelling and mapping the compositional turnover of both animal and plant species, using several different sources of remote sensing (and auxiliary) data (Leitão et al., 2015; Leitão, Schwieder, \& Senf, 2017).

\section{6 | RAO'S Q DIVERSITY}

Most of the previously shown metrics are based on the distance among pixel values in a multidimensional spectral space. None 


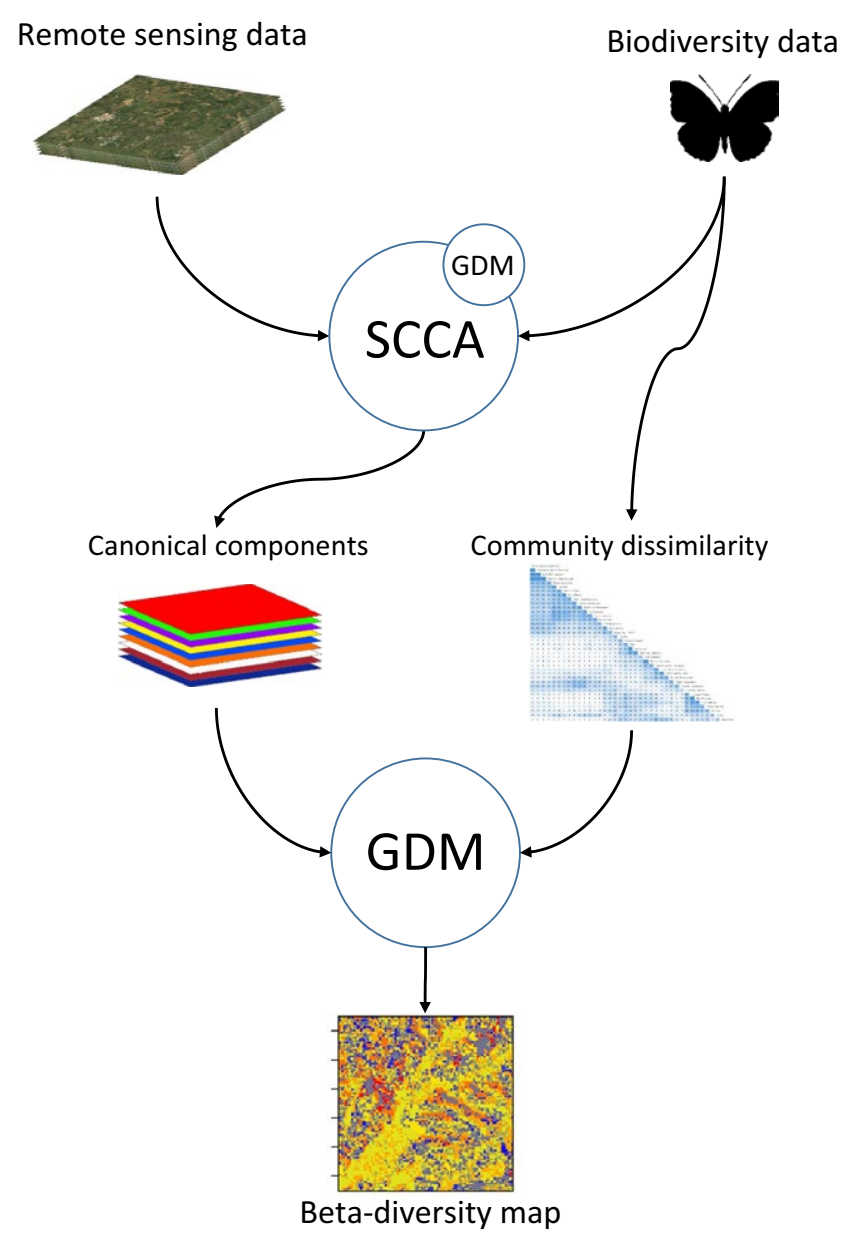

FIGURE 5 An example of the sparse generalized dissimilarity model approach. Remote sensing data and biodiversity data in the field can be coupled by sparse canonical correlation analysis (SCCA) to produce canonical components and a community dissimilarity matrix, which are then used to build a generalized dissimilarity model (GDM) to finally derive a $\beta$-diversity map

of them considers the relative abundance of such pixel values in a neighbourhood.

By contrast, abundance-based metrics such as the Shannon entropy could output similar results despite a variable distance among pixel values. As an example, consider a $3 \times 3$ matrix of remotely sensed data:

$$
\left(\begin{array}{lll}
x_{11} & x_{12} & x_{13} \\
x_{21} & x_{22} & x_{23} \\
x_{d 1} & x_{d 2} & x_{d 3}
\end{array}\right)
$$

composed by the following values:

$$
\left(\begin{array}{lll}
10 & 13 & 15 \\
18 & 20 & 23 \\
19 & 21 & 22
\end{array}\right)
$$

then consider a different matrix:

$$
\left(\begin{array}{ccc}
10 & 121 & 227 \\
1 & 40 & 251 \\
7 & 100 & 149
\end{array}\right)
$$

From a Shannon's entropy perspective, such matrices are equal in terms of heterogeneity. The Shannon's entropy is indeed based on the relative abundance (and richness) of a sample, and its value is 2.197 for both the matrices. This value, equalling the natural logarithm of the number of classes (pixel values), is also Shannon's maximum theoretical value given a $3 \times 3$ matrix, due to the lack of identical numbers in the matrices. This example explicitly shows that accounting for the distance among values and their relative abundance is crucial to discriminate among areas in terms of measured (modelled) heterogeneity.

One of the metrics accounting for both the abundance and the pairwise spectral distance among pixels is the Rao's Q diversity index, as follows:

$$
Q=\sum \sum d_{i j} \times p_{i} \times p_{j}
$$

where $d_{i j}=$ spectral distance among pixels $i$ and $j$ and $p=$ proportion of occupied area.

Hence, Rao's Q is capable of discriminating among the ecological diversity of matrices (3) and (4), turning out to be 4.59 and 90.70 , respectively. Appendix S1 provides an example spreadsheet to perform the calculation while the complete R code is stored in the GitHub repository https://github.com/mattmar/spectralrao.

We decided to make use of a case study to highlight the importance of considering the distance among pixel values in remote sense ecological application. The performance of Rao's $Q$ index in describing landscape diversity was tested in a complex agro-forestry landscape located in southern Portugal. A test site with an area of about $10 \times 10 \mathrm{~km}^{2}$ (centroid located at 38 39'10.74' $\mathrm{N} ; 8^{\circ} 12^{\prime} 52.30^{\prime \prime} \mathrm{W}$ ) was selected to conduct the analysis. In this area, a savanna-like ecosystem called montado occupies about $40 \%$ of the test site, followed by traditional olive groves, pastures, vineyards, and irrigated monocultures (e.g., corn fields). Montado is spatially characterized by the variability of its tree density (e.g., Godinho, Gil, Guiomar, Neves, \& Pinto-Correia, 2016), and the gradient between low and high tree density over space can lead to different structural heterogeneity and habitat diversity.

Within the test site, polyculture under the small farming context (e.g., vegetable gardens, orchards, and cereal crops) is an important feature of this landscape by generating a high compositional and configurational spatial heterogeneity (Figure 6). The main goal in using this case study is to demonstrate the potential and effectiveness of the Rao's $Q$ index in producing accurately remote sensing-based maps of spatial diversity over such complex landscape. For this study, a cloud-free Sentinel-2A (S2A) image acquired on August 8, 2016 was used to compute the NDVI at a $10 \mathrm{~m}$ spatial resolution. The S2A image download as well as the atmospheric correction (DOS method) were performed, using the Semi-automatic Classification plugin (SCP) implemented in the QGIS software (QGIS Development Team, 2016).

The NDVI was used as input data for Rao's $Q$ index computation, using a window size of $3 \times 3$ pixels. The performance of the Rao's $Q$ was compared to the Shannon Entropy index (Shannon's H), which is one of the simplest, and widely used, remote sensing-based diversity measures for landscape heterogeneity assessment (Rocchini et al., 2016). To investigate whether both diversity indices differ between 

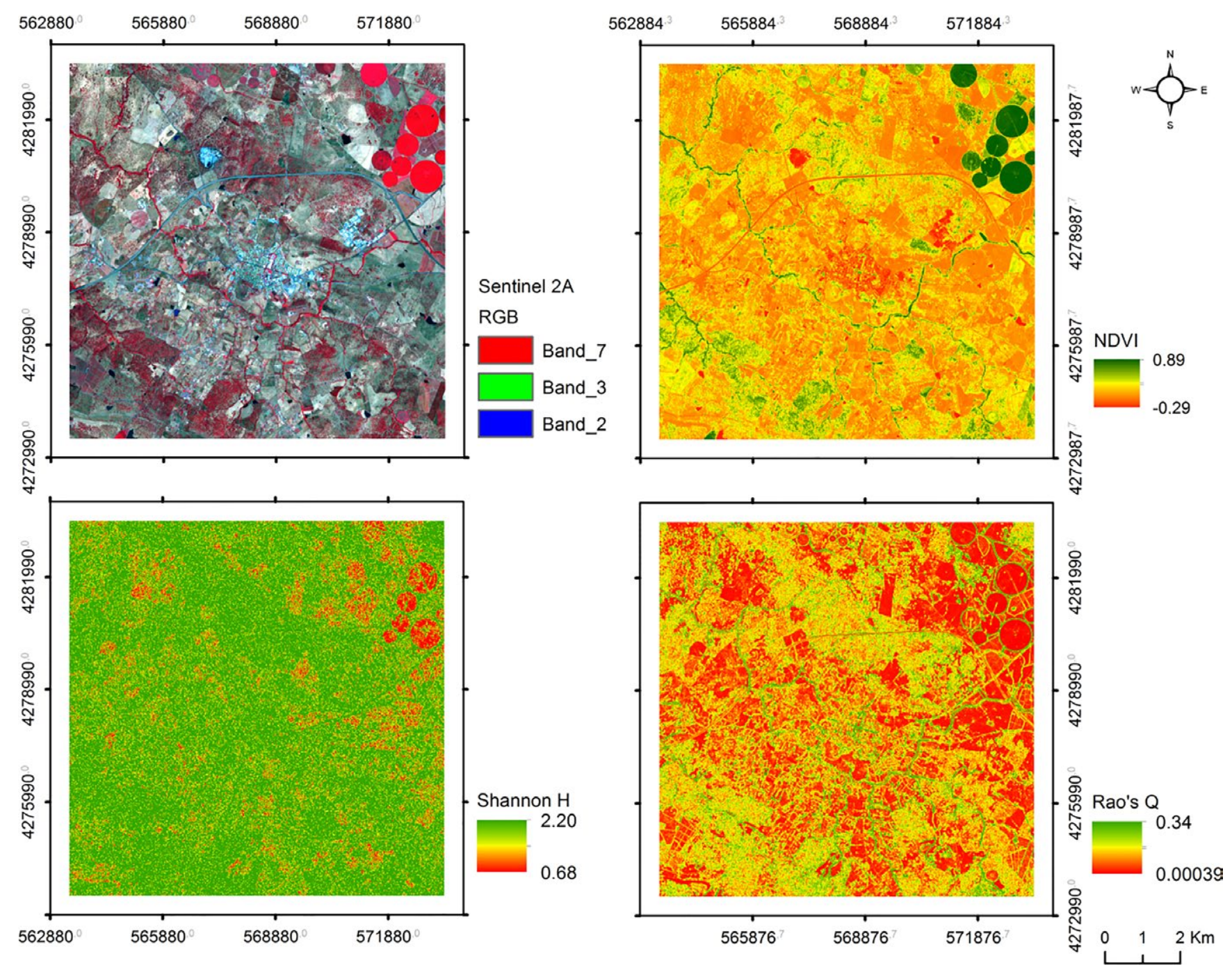

FIGURE 6 Upper panels: Sentinel-2A scene (August 8, 2016) and derived NDVI for the agro-forestry systems test site located in southern Portugal. Lower panels: results from Shannon's H and Rao's Q indices computation. Shannon index tends to overestimate the landscape diversity when compared to the Rao's Q index

land cover types, one-way ANOVA tests were performed. This approach was used for analysing the degree of dissimilarity between Rao's $\mathrm{Q}$ and Shannon $\mathrm{H}$ index across two high complex land cover types; (1) montado, and (2) polyculture. To do so, a sample of 60 squares with $250 \times 250 \mathrm{~m}^{2}$ size was randomly selected over these two land cover types. Each square represents a sample of 625 S2A NDVI pixels, thus corresponding to a total of 37,500 pixels over the 60 squares. For the comparison between both indices, the coefficient of variation (CV) was calculated for each $250 \times 250 \mathrm{~m}^{2}$. Regarding the Rao's Q performance, Figure 6 clearly points to the significant improvements shown by Rao's $Q$ index compared to the Shannon $\mathrm{H}$ index in describing the spatial diversity. In particular, it can be seen through the Figure 6, that Rao's Q index can highlight different gradients of spatial diversity of montado areas, which present high tree density variability (Figure 6), and thus high spatial heterogeneity. One-way ANOVA tests revealed that both indices values were significantly different between the two land cover types (montado: $F=503.3, p<.001$; polyculture: $F=889.8, p<.001$ ). Overall, the obtained results demonstrate the capability of Rao's Q index in producing accurate landscape diversity maps in a complex landscape such as the Mediterranean agro-forestry systems.

\section{7 | CONCLUSION}

In this paper, we showed several methods based on ecological $\beta$-diversity, which can be investigated by remote sensing through the calculation of ecosystem heterogeneity, to estimate the spatial variability of biodiversity. When there is a wide range of heterogeneity, for example, when the data include homogeneous and heterogeneous zones, no single measure might capture all the different aspects of $\beta$-diversity (e.g., Baselga, 2013). That is why we suggested in this manuscript multivariate and multidimensional methods (e.g., multivariate statistics and multidimensional distance matrices) based on the spectral signal and its variability over space to account for different aspects of diversity, also including distance- and abundance-based methods (e.g., the Rao's Q). 
Biodiversity measured as species richness is often used for conservation purposes, hence the importance of avoiding an under- or overestimate has been highlighted (Chiarucci et al., 2009). Furthermore, pairwise distance-based methods might be profitably used to detect not only diversity hotspots in an area but also the variation of biodiversity over space, and potentially over time, once multitemporal sets of images are used.

In this paper, we focused on optimizing measures of $\beta$-diversity based on remote sensing data. Such measures might be used to regress species diversity against remotely sensed heterogeneity, based on new regression techniques which maximize the possibility of predicting the zones in a study area, or at larger spatial scales, of peculiar conservation value. As an example, shrinkage regression, recently applied in biodiversity conservation (Authier, Saraux, \& Peron, 2017) could allow a direct focus on habitat modelling, which is one of the major strengths of remote sensing (Gillespie, Foody, Rocchini, Giorgi, \& Saatchi, 2008). Moreover, such analysis might be performed in a Bayesian framework allowing to (1) model multidimensional covariates with non-stationary variation over space (Randell, Turnbull, Ewans, \& Jonathan, 2016), such as the bands of satellite images, and (2) model the errors in the output and their variation over space (Rocchini et al., 2017).

As previously stated, the suggested methods for $\beta$-diversity estimation from remote sensing are mainly based on distances, but they could be effectively translated to relative abundance-based methods. As an example Rocchini et al. (2013) introduced the possibility of applying generalized entropy theory to satellite images with one single formula representing a continuum of diversity measures changing one parameter. One of the best examples in this framework could be the use of Hill numbers, in which diversity is expressed as follows:

$$
{ }^{a} D=\left(\sum_{i=1}^{S} p_{i}^{q}\right)^{\frac{1}{1-q}}
$$

where $S=$ number of samples/pixels and $p_{i}=$ relative abundance of a species/spectral value. varying the parameter $q,{ }^{a} D$ varies accordingly in several diversity indices, e.g. for $q=0{ }^{9} D$ is the simple number of species, for $\lim (q)=1^{a} D$ equals Shannon's entropy, etc. (Hsieh, Ma, $\&$ Chao, 2016).

Furthermore, connectivity analysis might also be taken into account (Moilanen et al., 2005, 2009). For instance, a remote sensing-based connectivity network among different sites, based on $\beta$-diversity measures, could be applied for the estimate of landscape connectivity and consequent genetic flow, as demonstrated by Vernesi et al. (2012). It has also been shown that community related biodiversity indicators are often missing from current monitoring programmes (Vihervaara et al., 2017); thus methods such as remote sensing-based Rao's Q diversity applied for various ecosystems might improve otherwise challenging monitoring of biological communities.

With this manuscript, we hope to stimulate discussion on the available methods for estimating $\beta$-diversity from remotely sensed imagery by proposing innovative techniques grounded on ecological theory.

\section{ACKNOWLEDGEMENTS}

We are grateful to the handling Editor and to two anonymous reviewers who improved with skillful suggestions a previous version of the present manuscript. D.R. was partially supported by: (i) the EU-LIFE project LIFE14ENV/IT/000514 FutureForCoppices, (ii) the H2020 project ECOPOTENTIAL (Grant Agreement no. 641762), iii) the H2020 TRuStEE - Training on Remote Sensing for Ecosystem modElling - project (Grant Agreement no. 721995).

\section{AUTHORS' CONTRIBUTIONS}

All authors contributed to the development and writing of the manuscript.

\section{DATA ACCESSIBILITY}

Part of the data and corresponding original sources are available at the following https://doi.org/10.5061/dryad.dg31k.

\section{ORCID}

Duccio Rocchini (iD http://orcid.org/0000-0003-0087-0594

Sandra Luque iD http://orcid.org/0000-0002-4002-3974

Nathalie Pettorelli iD http://orcid.org/0000-0002-1594-6208

Lucy Bastin (iD http://orcid.org/0000-0003-1321-0800

Hannes Feilhauer (iD http://orcid.org/0000-0001-5758-6303

Jean-Baptiste Féret iD http://orcid.org/0000-0002-0151-1334

Giles M. Foody iD http://orcid.org/0000-0001-6464-3054

Yoni Gavish (iD http://orcid.org/0000-0002-6025-5668

William E. Kunin (D) http://orcid.org/0000-0002-9812-2326

Angela Lausch iD http://orcid.org/0000-0002-4490-7232

Pedro J. Leitão (ID http://orcid.org/0000-0003-3038-9531

Markus Neteler iD http://orcid.org/0000-0003-1916-1966

Carlo Ricotta (iD http://orcid.org/0000-0003-0818-3959

Martin Wegmann (iD http://orcid.org/0000-0003-0335-9601

Harini Nagendra iD http://orcid.org/0000-0002-1585-0724

\section{REFERENCES}

Alahuhta, J., Kosten, S., Akasaka, M., Auderset, D., Azzella, M., Bolpagni, R., ... Heino, J. (2017). Global variation in the beta diversity of lake macrophytes is driven by environmental heterogeneity rather than latitude. Journal of Biogeography, 44, 1758-1769. https://doi.org/10.1111/jbi.12978

Asner, G., \& Martin, R. (2008). Spectral and chemical analysis of tropical forests: Scaling from leaf to canopy levels. Remote Sensing of Environment, 112, 3958-3970. https://doi.org/10.1016/j.rse.2008.07.003

Asner, G. P., Martin, R. E., Anderson, C. B., \& Knapp, D. E. (2015). Quantifying forest canopy traits: Imaging spectroscopy versus field survey. Remote Sensing of Environment, 158, 15-27. https://doi.org/10.1016/j.rse.2014. 11.011 
Authier, M., Saraux, C., \& Peron, C. (2017). Variable selection and accurate predictions in habitat modelling: A shrinkage approach. Ecography, 40 , 549-560. https://doi.org/10.1111/ecog.01633

Baldeck, C., \& Asner, G. (2013). Estimating vegetation beta diversity from airborne imaging spectroscopy and unsupervised clustering. Remote Sensing, 5, 2057-2071. https://doi.org/10.3390/rs5052057

Baldeck, C. A., \& Colgan, M. S., Féret, J.-B., Levick, S. R., Martin, R. E., \& Asner, G. P. (2014). Landscape-scale variation in plant community composition of an African savanna from airborne species mapping. Ecological Applications, 24, 84-93. https://doi.org/10.1890/13-0307.1

Baselga, A. (2013). Multiple site dissimilarity quantifies compositional heterogeneity among several sites, while average pairwise dissimilarity may be misleading. Ecography, 36, 124-128. https://doi.org/10.1111/ j.1600-0587.2012.00124.x

Chadwick, K., \& Asner, G. (2016). Organismic-scale remote sensing of canopy foliar traits in lowland tropical forests. Remote Sensing, 8, 87. https://doi.org/10.3390/rs8020087

Chiarucci, A., Bacaro, G., Rocchini, D., Ricotta, C., Palmer, M. W., \& Scheiner, S. M. (2009). Spatially constrained rarefaction: Incorporating the autocorrelated structure of biological communities in sample-based rarefaction. Community Ecology, 10, 209-214. https://doi.org/10.1556/ comec.10.2009.2.11

Chon, T.-S., Park, Y. S., Moon, K. Y., \& Cha, E. Y. (1996). Patternizing communities by using an artificial neural network. Ecological Modelling, 90 , 69-78. https://doi.org/10.1016/0304-3800(95)00148-4

Clark, M. L., \& Roberts, D. A. (2012). Species-level differences in hyperspectral metrics among tropical rainforest trees as determined by a tree-based classifier. Remote Sensing, 4, 1820-1855. https://doi. org/10.3390/rs4061820

Clark, M., Roberts, D., \& Clark, D. (2005). Hyperspectral discrimination of tropical rain forest tree species at leaf to crown scales. Remote Sensing of Environment, 96, 375-398. https://doi.org/10.1016/j.rse.2005.03.009

Feilhauer, H., \& Schmidtlein, S. (2009). Mapping continuous fields of alpha and beta diversity. Applied Vegetation Science, 12, 429-439. https://doi. org/10.1111/j.1654-109x.2009.01037.x

Feilhauer, H., Faude, U., \& Schmidtlein, S. (2011). Combining Isomap ordination and imaging spectroscopy to map continuous floristic gradients in a heterogeneous landscape. Remote Sensing of Environment, 115, 2513-2524. https://doi.org/10.1016/j.rse.2011.05.011

Feilhauer, H., Thonfeld, F., Faude, U., , He, K. S., Rocchini, D., Schmidtlein, S. (2013). Assessing floristic composition with multispectral sensors a comparison based on monotemporal and multiseasonal field spectra. International Journal of Applied Earth Observation and Geoinformation, 21, 218-229. https://doi.org/10.1016/j.jag.2012.09.002

Feilhauer, H., Doktor, D., Lausch, A., Schmidtlein, S., Schulz, G., \& Stenzel, S. (2014). Mapping Natura 2000 habitats and their local variability with remote sensing. Applied Vegetation Science, 17, 765-779. https://doi. org/10.1111/avsc.12115

Feilhauer, H., Doktor, D., Schmidtlein, S., \& Skidmore, A. K. (2016). Mapping pollination types with remote sensing. Journal of Vegetation Science, 27 999-1011. https://doi.org/10.1111/jvs.12421

Féret, J.-B., \& Asner, G. P. (2013). Tree species discrimination in tropical forests using airborne imaging spectroscopy. IEEE Transactions on Geoscience and Remote Sensing, 51, 73-84. https://doi.org/10.1109/TG RS.2012.2199323

Féret, J.-B., \& Asner, G. P. (2014a). Mapping tropical forest canopy diversity using high-fidelity imaging spectroscopy. Ecological Applications, 24, 1289-1296. https://doi.org/10.1890/13-1824.1

Féret, J.-B., \& Asner, G. P. (2014b). Microtopographic controls on lowland Amazonian canopy diversity from imaging spectroscopy. Ecological Applications, 24, 1297-1310. https://doi.org/10.1890/13-1896.1

Ferrier, S., Manion, G., Elith, J. \& Richardson, K. (2007). Using generalized dissimilarity modelling to analyse and predict patterns of beta diversity in regional biodiversity assessment. Diversity and Distributions, 13, 252-264. https://doi.org/10.1111/j.1472-4642.2007.00341.x
Foody, G. M. (1999). Applications of the self-organising feature map neural network in community data analysis. Ecological Modelling, 120, 97-107. https://doi.org/10.1016/s0304-3800(99)00094-0

Foody, G. M., \& Cutler, M. E. J. (2003). Tree biodiversity in protected and logged Bornean tropical rain forests and its measurement by satellite remote sensing. Journal of Biogeography, 30, 1053-1066. https://doi. org/10.1046/j.1365-2699.2003.00887.x

Fritzke, B. (1995). Growing grid - A self organizing network with constant neighborhood range and adaptation strength. Neural Processing Letters, 2, 9-13. https://doi.org/10.1007/bf02332159

Gillespie, T. W. (2005). Predicting woody-plant species richness in tropical dry forests: a case study from South Florida, USA. Ecological Applications, 15, 27-37. https://doi.org/10.1890/03-5304

Gillespie, T. W., Foody, G. M., Rocchini, D., Giorgi, A. P., \& Saatchi, S. (2008). Measuring and modeling biodiversity from space. Progress in Physical Geography, 32, 203-221. https://doi.org/10.1177/03091333 08093606

Giraudel, J. L., \& Lek, S. (2001). A comparison of SOM algorithm and some conventional statistical methods for ecological community ordination. Ecological Modelling, 146, 329-339. https://doi.org/10.1016/ s0304-3800(01)00324-6

Godinho, S., Gil, A., Guiomar, N., Neves, N. \& Pinto-Correia, T. (2016). A remote sensing-based approach to estimating montado canopy density using the FCD model: A contribution to identifying HNV farmlands in southern Portugal. Agroforestry Systems, 90, 23-34. https://doi. org/10.1007/s10457-014-9769-3

Graham, C. H., \& Fine, P.V.A. (2008). Phylogenetic beta diversity: Linking ecological and evolutionary processes across space in time. Ecology Letters, 11, 1265-1277. https://doi.org/10.1111/j.1461-0248.2008.01256.x

Gu, H., Singh, A., \& Townsend, P. A. (2015). Detection of gradients of forest composition in an urban area using imaging spectroscopy. Remote Sensing of Environment, 167, 168-180. https://doi.org/10.1016/j. rse.2015.06.010

Harris, A., Charnock, R., \& Lucas, R. M. (2015). Hyperspectral remote sensing of peatland floristic gradients. Remote Sensing of Environment, 162, 99-111. https://doi.org/10.1016/j.rse.2015.01.029

Hernandez-Stefanoni, J. L., Gallardo-Cruz, J. A., Meave, J. A., Rocchini, D., Bello-Pineda, J., \& López-Martínez, J. O. (2012). Modeling $\alpha$ - and $\beta$-diversity in a tropical forest from remotely sensed and spatial data. International Journal of Applied Earth Observation and Geoinformation, 19, 359-368. https://doi.org/10.1016/j.jag.2012.04.002

Hill, M. O., \& Gauch, H. G., 1980. Detrended correspondence analysis: An improved ordination technique. Vegetatio, 42, 47-58. https://doi. org/10.1007/978-94-009-9197-2_7

Hsieh, T. C., Ma, K. H., \& Chao, A. (2016). INEXT: An R package for rarefaction and extrapolation of species diversity (Hill numbers). Methods in Ecology \& Evolution, 7, 1451-1456. https://doi.org/10.1111/2041-210x.12613

Kohonen, T. (1982). Analysis of a simple self-organizing process. Biological Cybernetics, 44, 135-140. https://doi.org/10.1007/bf00317973

Latombe, G., Hui, C., \& McGeoch, M. A. (2017). Multi-site generalised dissimilarity modelling: Using zeta diversity to differentiate drivers of turnover in rare and widespread species. Methods in Ecology and Evolution, 8, 431-442. https://doi.org/10.1111/2041-210x.12756

Lausch, A., Bannehr, L., Beckmann, M., Boehm, C., Feilhauer, H., Hacker, J. M., ... Cord, A. F. (2016). Linking earth observation and taxonomic, structural and functional biodiversity: Local to ecosystem perspectives. Ecological Indicators, 70, 317-339. https://doi.org/10.1016/j. ecolind.2016.06.022

Leathwick, J. R., Snelder, T., Chadderton, W. L., Elith, J., Julian, K., \& Ferrier, S. (2011). Use of generalised dissimilarity modelling to improve the biological discrimination of river and stream classifications. Freshwater Biology, 56, 21-38. https://doi.org/10.1111/j.1365-2427.2010.02414.x

Legendre, P., Borcard, D., \& Peres-Neto, P. R. (2005). Analyzing beta diversity: Partitioning the spatial variation of community composition data. Ecological Monographs, 75, 435-450. https://doi.org/10.1890/05-0549 
Leitão, P. J., Schwieder, M., Suess, S., Catry, I., Milton, E. J., Moreira, F., ... Hostert, P. (2015). Mapping beta diversity from space: Sparse generalised dissimilarity modelling (SGDM) for analysing high-dimensional data. Methods in Ecology and Evolution, 6, 764-771. https://doi. org/10.1111/2041-210x.12378

Leitão, P., Schwieder, M.,\& Senf, C. (2017). sGDM: An R package for performing sparse generalized dissimilarity modelling with tools for GDM. ISPRS International Journal of Geo-Information, 6, 23. https://doi.org/10.3390/ ijgi6010023

Mantel, N., \& Valand, R. S. (1970). A technique of nonparametric multivariate analysis. Biometrics, 26, 547-558. https://doi.org/10.2307/2529108

Mazor, T., Kark, S., Possingham, H. P., Rocchini, D., Levy, Y., Richardson, A. J., \& Levin, N. (2013). Can satellite-based night lights be used for conservation? The case of nesting sea turtles in the Mediterranean. Biological Conservation, 159, 63-72. https://doi.org/10.1016/j.biocon.2012.11. 004

Meentemeyer, R. K., Anacker, B. L., Mark, W., \& Rizzo, D. M. (2008). Early detection of emerging forest disease using dispersal stimation and ecological niche modeling. Ecological Applications, 18, 377-390. https:// doi.org/10.1890/07-1150.1

Metz, M., Rocchini, D., \& Neteler, M. (2014). Surface temperatures at the continental scale: Tracking changes with remote sensing at unprecedented detail. Remote Sensing, 6, 3822-3840. https://doi.org/10.3390/ rs6053822

Moilanen, A., Franco, A. M. A., Early, R., Fox, R., Wintle, B., \& Thomas, C. D. (2005). Prioritizing multiple-use landscapes for conservation: Methods for large multi-species planning problems. Proceedings of the Royal Society B: Biological Sciences, 272, 1885-1891. https://doi. org/10.1098/rspb.2005.3164

Moilanen, A., Kujala, H., \& Leathwick, J. R. (2009). The zonation framework and software for conservation prioritization. In A. Moilanen, K. Wilson, \& H. P. Possingham (Eds.), Spatial conservation prioritization: Quantitative methods \& computational tools (pp. 196-210). Oxford: Oxford University Press.

Neumann, C., Weiss, G., Schmidtlein, S., Itzerott, S., Lausch, A., Doktor, D., \& Brell, M. (2015). Ecological gradient-based habitat quality assessment for spectralecosystem monitoring. Remote Sensing, 7, 2871-2898. https://doi.org/10.3390/rs70302871

Palmer, M. W., Earls, P. G., Hoagland, B. W., White, P. S., \& Wohlgemuth, T. (2002). Quantitative tools for perfecting species lists. Environmetrics, 13, 121-137. https://doi.org/10.1002/env.516

QGIS Development Team. (2016). QGIS geographic information system. Open Source Geospatial Foundation. Available at http://qgis.osgeo. org

Randell, D., Turnbull, K., Ewans, K., \& Jonathan, P. (2016). Bayesian inference for nonstationary marginal extremes. Environmetrics, 27, 439450. https://doi.org/10.1002/env.2403

Rocchini, D. Petras, V., Petrasova, A., Horning, N., Furtkevicova, L., Neteler, M., ... Wegmann, M. (2017). Open data and open source for remote sensing training in ecology. Ecological Informatics, 40, 57-61.

Rocchini, D., \& Neteler, M. (2012). Let the four freedoms paradigm apply to ecology. Trends in Ecology \& Evolution, 27, 310-311. https://doi. org/10.1016/j.tree.2012.03.009

Rocchini, D., Andreini Butini, S., \& Chiarucci, A. (2005). Maximizing plant species inventory efficiency by means of remotely sensed spectral distances. Global Ecology and Biogeography, 14, 431-437. https://doi. org/10.1111/j.1466-822x.2005.00169.x

Rocchini, D., Balkenhol, N., Carter, G. A., Foody, G. M. Gillespie, T. W., He, K. S., ... Neteler, M. (2010). Remotely sensed spectral heterogeneity as a proxy of species diversity: Recent advances and open challenges. Ecological Informatics, 5, 318-329. https://doi.org/10.1016/j. ecoinf.2010.06.001

Rocchini, D., Delucchi, L., Bacaro, G., Cavallini, P., Feilhauer, H., Foody, G. M., ... Neteler, M. (2013). Calculating landscape diversity with information-theory based indices: A GRASS GIS solution. Ecological Informatics, 17, 82-93. https://doi.org/10.1016/j.ecoinf.2012.04.002

Rocchini, D., Hernández Stefanoni, J. L., \& He, K. S. (2015). Advancing species diversity estimate by remotely sensed proxies: A conceptual review. Ecological Informatics, 25, 22-28. https://doi.org/10.1016/j. ecoinf.2014.10.006

Rocchini, D., Boyd, D. S., Féret, J. B., Foody, G. M., He, K. S., Lausch, A., ... Pettorelli, N. (2016). Satellite remote sensing to monitor species diversity: Potential and pitfalls. Remote Sensing in Ecology and Conservation, 2, 25-36. https://doi.org/10.1002/rse2.9

Rocchini, D., Garzon-Lopez, C. X., Marcantonio, M., Amici, V., Bacaro, G., Bastin, L., ... Rosá, R. (2017). Anticipating species distributions: Handling sampling effort bias under a Bayesian framework. Science of the Total Environment, 584-585, 282-290. https://doi.org/10.1016/j. scitotenv.2016.12.038

Rosauer, D. F., Ferrier, S., Williams, K. J., Manion, G., Keogh, J. S., \& Laffan, S. W. (2014). Phylogenetic generalised dissimilarity modelling: A new approach to analysing and predicting spatial turnover in the phylogenetic composition of communities. Ecography, 37, 21-32. https://doi. org/10.1111/j.1600-0587.2013.00466.x

Schmeller, D., Weatherdon, L., Loyau, A., Bondeau, A., Brotons, L., Brummitt, N., ... Regan, E. (in press). A suite of essential biodiversity variables for detecting critical biodiversity change. Biological Reviews.

Schmidtlein, S., \& Sassin, J. (2004). Mapping continuous floristic gradients in grasslands using hyperspectral imagery. Remote Sensing of Environment, 92, 126-138. https://doi.org/10.1016/j.rse.2004.05.004

Schmidtlein, S., Zimmermann, P., Schüpferling, R., \& Weiss, C. (2007). Mapping the floristic continuum: Ordination space position estimated from imaging spectroscopy. Journal of Vegetation Science, 18, 131-140. https://doi.org/10.1111/j.1654-1103.2007.tb02523.x

Tahvanainen, T. (2011). Abrupt ombrotrophication of a boreal aapa mire triggered by hydrological disturbance in the catchment. Journal of Ecology, 2011, 99,

Tuomisto, H., \& Ruokolainen, K. (2006). Analyzing or explaining beta diversity? Understanding the targets of different methods of analysis. Ecology, 87, 2697-2708. https://doi.org/10.1890/0012-9658 (2006)87

Tuomisto, H., Poulsen, A., Ruokolainen, K., Moran, R., Quintana, C., Celi, J., \& Canas, G. (2003). Linking floristic patterns with soil heterogeneity and satellite imagery in Ecuadorian Amazonia. Ecological Applications, 13, 352-371. https://doi.org/10.1890/1051-0761(2003)013[0352:Ifp wsh]2.0.co; 2

Tyre, A. J., Possingham, H. P., \& Lindenmayer, D. B. (2001). Inferring process from pattern: Can territory occupancy provide information about life history parameters? Ecological Applications, 11, 1722-1737. https://doi. org/10.2307/3061091

Ustin, S. L., \& Gamon, J. A. (2010). Remote sensing of plant functional types. New Phytologist, 186, 795-816. https://doi.org/10.1111/j.14698137.2010.03284.x

Vaglio Laurin, G., Chan, J. C.-W., Chen, Q., Lindsell, J. A., Coomes, D. A., Guerriero, L., ... Valentini, R. (2014). Biodiversity mapping in a tropical West African forest with airborne hyperspectral data. PLoS ONE, 9, e97910. https://doi.org/10.1371/journal.pone.0097910

Vernesi, C., Rocchini, D., Pecchioli, E., Neteler, M., Vendramin, G. G., \& Paffetti, D. (2012). A landscape genetics approach reveals ecological-based differentiation in populations of holm oak (Quercus ilex, L.) at their northernmost distribution EDGE. Biological Journal of the Linnean Society, 107, 458-467. https://doi.org/10.1111/j.1095-8312. 2012.01940.x

Vihervaara, P., Auvinen, A.-P, Mononen, L., Törmä, M., Ahlroth, P., Anttila, S., ... Virkkala, R. (2017). How essential biodiversity variables and remote sensing can help national biodiversity monitoring. Global Ecology and Conservation, 10, 43-59. https://doi.org/10.1016/j.gecco.2017. 01.007 
Wegmann, M., Leutner, B. F., Metz, M., Neteler, M., Dech, S., \& Rocchini, D. (2017). R.PI: A GRASS GIS package for semi-automatic spatial pattern analysis of remotely sensed land cover data. Methods in Ecology and Evolution, in press. https://doi.org/10.1111/2041-210x.12827

Whittaker, R. H. (1960). Vegetation of the Siskiyou Mountains, Oregon and California. Ecological Monographs, 30, 280-338. https://doi.org/10. 2307/1943563

Witten, D., Tibshirani, R., Gross, S., \& Narasimhan, B. (2013). PMA: Penalized multivariate analysis. $\mathrm{R}$ package version 1.0.9. Retrieved from https://CRAN.R-project.org/package=PMA

Woolley, S. N. C., Foster, S. D., O'Hara, T. D., Wintle, B. A., \& Dunstan, P. K. (2017). Characterising uncertainty in generalised dissimilarity models. Methods in Ecology and Evolution, 8, 985-995. https://doi. org/10.1111/2041-210x.12710

\section{SUPPORTING INFORMATION}

Additional Supporting Information may be found online in the supporting information tab for this article.

How to cite this article: Rocchini D, Luque S, Pettorelli N, et al. Measuring $\beta$-diversity by remote sensing: A challenge for biodiversity monitoring. Methods Ecol Evol. 2018;9:1787-

1798. https://doi.org/10.1111/2041-210X.12941 